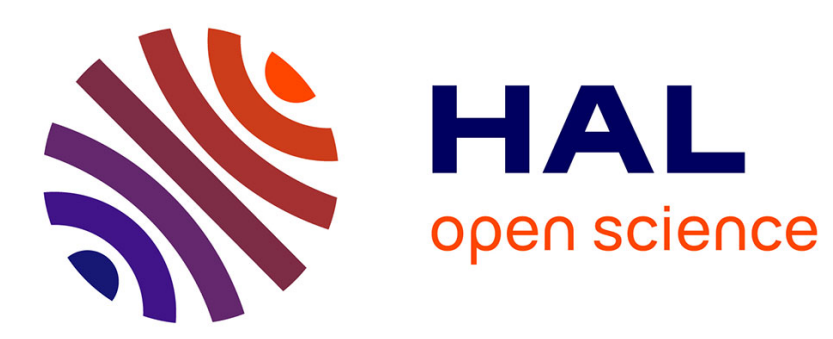

\title{
Acrylamide formation in low-fat potato snacks and its correlation with color development
}

Malgorzata A. Majcher, Henryk H. Jeleñ

\section{To cite this version:}

Malgorzata A. Majcher, Henryk H. Jeleñ. Acrylamide formation in low-fat potato snacks and its correlation with color development. Food Additives and Contaminants, 2007, 24 (04), pp.337-342. 10.1080/02652030601185709 . hal-00577543

\section{HAL Id: hal-00577543 \\ https://hal.science/hal-00577543}

Submitted on 17 Mar 2011

HAL is a multi-disciplinary open access archive for the deposit and dissemination of scientific research documents, whether they are published or not. The documents may come from teaching and research institutions in France or abroad, or from public or private research centers.
L'archive ouverte pluridisciplinaire HAL, est destinée au dépôt et à la diffusion de documents scientifiques de niveau recherche, publiés ou non, émanant des établissements d'enseignement et de recherche français ou étrangers, des laboratoires publics ou privés. 


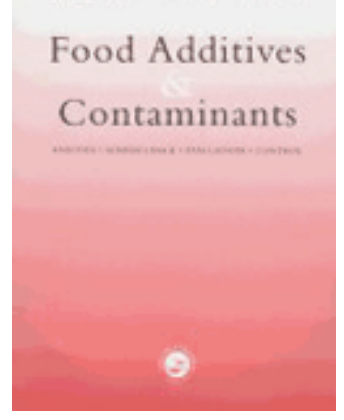

\section{Acrylamide formation in low-fat potato snacks and its correlation with color development}

\begin{tabular}{|r|l|}
\hline Journal: & Food Additives and Contaminants \\
\hline Manuscript ID: & TFAC-2006-247.R1 \\
\hline Manuscript Type: & Original Research Paper \\
\hline Author: & 12-Dec-2006 \\
\hline Complete List of Authors: & $\begin{array}{l}\text { Majcher, Malgorzata; Agricultural University of Poznañ, Food } \\
\text { Science and Nutrition } \\
\text { Jeleñ, Henryk; Agricultural University of Poznañ, Food Science and } \\
\text { Nutrition }\end{array}$ \\
\hline Methods/Techniques: & Chromatography - GC/MS \\
\hline Additives/Contaminants: & Acrylamide \\
\hline Food Types: & Snack products \\
\hline
\end{tabular}

\section{SCHOLARONE ${ }^{m}$ Manuscripts}




\section{Acrylamide formation in low-fat potato snacks and its correlation with} 4 colour development

6 Małgorzata A. Majcher, Henryk H. Jeleń*

8 Department of Food Science and Nutrition,

9 The August Cieszkowski Agricultural University of Poznań, Wojska Polskiego 31, 10 60-624 Poznań, Poland

$12{ }^{*}$ Corresponding author: Department of Food Science and Nutrition, The August 13 Cieszkowski Agricultural University of Poznań, Wojska Polskiego 31, 60-624 Poznań, 14 Poland (telephone 004861-8487273; fax 004861-8487314; e-mail: 15 henrykj@au.poznan.pl

17 Abstract

18 In the Institute of Food Technology of Plant Origin at Agricultural University of Poznań 19 a recipe and technological process for production of low-fat potato snacks ( $7 \%$ of fat), 20 using a combination of extrusion and a roasting process was developed. Due to the 21 character of the product obtained, the amount of acrylamide was analyzed. At the 22 same time, the influence of temperature and time of heating on the levels of acrylamide 23 were monitored as well as correlated with colour development and acrylamide content. 24 The amount of acrylamide determined in low-fat potato snacks was $489 \mu \mathrm{g} \mathrm{kg}^{-1} \pm 26 \mu \mathrm{g}$ 
$25 \mathrm{~kg}^{-1}$, which is comparable to that of French fries, crackers and cookies and almost three 26 times less than in potato chips analyzed by other authors. At the same time it was 27 shown that temperature and length of heating time have a significant influence on 28 acrylamide formation, with temperature having a stronger effect than time. 29 Measurement of the colour and the acrylamide content in low-fat potato snacks 30 produced using different temperatures and time of roasting showed that there is a 31 substantial correlation between lightness $\left(L^{*}\right)$, redness $\left(a^{*}\right)$ and yellowness $\left(b^{*}\right)$ and 32 acrylamide concentration as a function of time: $r^{2}=-0.995, R^{2}=0.996, r^{2}=0.998$ 33 respectively. Graduated increases in roasting temperatures showed correlation 34 between lightness $\left(L^{*}\right)$ or redness $\left(a^{*}\right)$ and acrylamide concentration: $r^{2}=-0.947$ and $r^{2}$ $35=0.968$. Yellowness $\left(b^{\star}\right)$ was not correlated with acrylamide content as a function of 36 temperature.

37

38 Keywords: low-fat potato snacks, acrylamide, colour development, gas 39 chromatography-mass spectrometry, (GC-MS/MS) 


\section{Introduction}

42 The high temperature used for the preparation of potato snacks to bring a pleasant 43 flavor and colour can also at the same time cause the development of toxic substances 44 such as acrylamide (2-propenamide). Since the year 2002 when a group of Swedish 45 researchers announced the presence of acrylamide in a wide range of fried or oven46 treated foods, many product types have been investigated. The highest amounts of 47 acrylamide were found to be in fried and baked potato products followed by cereal 48 products, whereas only low amounts of acrylamide were found in meat products (Ahn 49 et al. 2002, Becalski et al. 2003). Since acrylamide is known to be a neurotoxin, a carcinogen in animals and a probable carcinogen to humans as defined by the

51 International Agency for Research on Cancer (IARC, 1994) it is a concern of food 52 technologists to decrease its amount to the lowest possible levels.

53

54 There are several hypotheses concerning formation of acrylamide in cooked foods, 55 among which the Maillard browning reaction involving free asparagine and reducing 56 sugars is the most likely and frequently described mechanism (Mottram et al., 2004).

57 The second pathway considered for acrylamide formation is degradation of glycerol to 58 acroleine and later to acrylic acid, which in reaction with ammonia can develop into 59 acrylamide (Becalski et al. 2003). The optimal temperature for acrylamide formation 60 has been shown to range from $140^{\circ} \mathrm{C}$ to $180^{\circ} \mathrm{C}$ (Freidman 2003, Elmore et al. 2005). 61 The Maillard reaction is being used intentionally to develop a nice, desirable texture, 62 flavor and colour of the food product. Several factors are known to influence the colour 63 formation, such as $\mathrm{pH}$, water content and activity, oxygen level but most important is 64 temperature and length of heating time. Increase in temperature by $10^{\circ} \mathrm{C}$ speeds up a 65 non-enzymatic browning reaction by factors of 3-4 times (Belitz et al. 2004). 
67 Potato-based products represent an important part of the daily intake of mainly the 68 adolescent population from western countries. The most well-known and most popular 69 are French fries and potato chips which, beside high fat content (30-45\%), also cause 70 concern as the products with the highest amount of acrylamide. World interest in 71 healthier way of life has driven the food industry to find new ways to obtain food 72 products with lower oil content, while still retaining desirable texture and flavor. The 73 authors recent paper has introduced an extrusion process followed by roasting as a 74 way of producing low fat (7\%) potato snacks (Majcher and Jeleń 2005).

76 The colour of the food surface is the first quality parameter evaluated by consumers 77 and it is critical in the acceptance of the product. At the same time, colour can be easily 78 measured as an indication of other Maillard reaction products such as acrylamide. The 79 most popular and the easiest way of food colour measurement was introduced by the 80 Commission Internationale d'Eclairage (CIE) in 1976, where the colour is described in 81 a three-dimensional scale represented by the $L^{*} a^{*} b^{*}$ values. According to CIE, $L^{*}$ 82 indicates the level of light and dark, $a^{*}$ value indicates redness or greenness and $b^{*}$ 83 value indicates values of yellowness or blueness (Papadakis et al. 2000). Additionally 84 the newest paper by Gökmen et. al (2007) presents possibilities of employment 85 computer vision-based analysis which uses digital colour images for the estimation of 86 acrylamide content in food products.

88 The aim of this study was to (i) calculate the amount of acrylamide in low-fat potato snacks obtained by extrusion cooking and roasting, (ii) investigate the influence of

90 roasting time and temperature on acrylamide formation and (iii) examine the correlation 91 of the colour and acrylamide concentration in low-fat potato snacks as a function of 92 roasting time and temperature.

\section{Materials and methods}




\section{Chemicals}

95 Acrylamide (99\%) and d3-acrylamide (isotopic purity 98\%) were commercially available 96 from Aldrich (Poznań, Poland) and Cambridge Isotope Laboratories (Andover, MA, 97 USA), respectively; acetonitrile, potassium bromide, hydrobromic acid were obtained 98 from Sigma-Aldrich (Poznań, Poland); $n$-hexane, sodium thiosulfite, ethyl acetate, 99 saturated bromine water were from Chempur (Tarnowskie Góry, Poland); anhydrous 100 sodium sulfide was obtained from POCh (Gliwice, Poland). All chemicals were of 101 analytical grade. SEP-PAK Silica cartridges for extract purification were purchased 102 from Waters (Warsaw, Poland).

\section{Preparation of extruded potato snacks}

104 Experiments were conducted with extruded potato snack produced according a recipe 105 developed by us using a procedure described in the aforementioned paper (Majcher 106 and Jeleń 2005). After extrusion, products were cut into small pieces and heated in an 107 oven at $85^{\circ} \mathrm{C}$ for $15 \mathrm{~min}$ followed by $45 \mathrm{~min}$ of roasting at $130^{\circ} \mathrm{C}$ to develop proper 108 texture and aroma.

\section{Extraction of acrylamide}

110 The analysis was based on a previously described (Castle, 1993) method based on 111 bromination of acrylamide into 2-bromopropenamide, followed by GC/MS/MS analysis. 112 Extruded and roasted potato snacks $(20 \mathrm{~g})$ were ground and mixed with water $(150 \mathrm{ml})$, 113 spiked with $100 \mu \mathrm{l}$ of $100 \mathrm{mg} \mathrm{l}^{-1} \mathrm{~d}_{3}$-acrylamide internal standard, homogenized during 5 $114 \mathrm{~min}$ and centrifuged after at $14 \mathrm{j} 000 \mathrm{rpm}$ for $15 \mathrm{~min} .20 \mathrm{ml}$ of the organic extract was 115 transferred to $100 \mathrm{ml}$ screw-top vial and bromination reagents were added: $5 \mathrm{~g}$ of 116 potassium bromide; $0.2 \mathrm{ml}$ of hydrobromic acid; $4 \mathrm{ml}$ of saturated bromine water. The 117 entire mixture was stirred and set aside in a refrigerator at $4^{\circ} \mathrm{C}$ overnight. Excess 118 bromine was then neutralized by the addition of $0.7 \mathrm{M}$ sodium thiosulfite solution until 119 yellow colour disappeared. The mixture was then extracted with ethyl acetate $(2 \times 5 \mathrm{ml})$ 
120 using mechanical shaker for $10 \mathrm{~min}$. After separation the organic layer was collected 121 and filtered through anhydrous sodium sulfate and concentrated to $\sim 30 \mu$ under a soft 122 stream of nitrogen. To remove the last traces of ethyl acetate, $200 \mu \mathrm{l}$ of hexane was 123 added and than evaporated to dryness. The residue was re-dissolved in $20 \% \mathrm{v} / \mathrm{v}$ ethyl 124 acetate/hexane $(250 \mu \mathrm{l})$ prior to cleanup. A SPE-silica cartridge was preconditioned 125 with $7 \mathrm{ml} \mathrm{20 \%}$ ethyl acetate/hexane and the sample was applied. The cartridge was 126 eluted with $6 \mathrm{ml} \mathrm{30 \%} \mathrm{ethyl} \mathrm{acetate/hexane} \mathrm{and} \mathrm{the} \mathrm{first} 2 \mathrm{ml}$ was discarded. The rest of 127 the eluate was collected in an amber vial, and finally evaporated to a volume of $\sim 50 \mu \mathrm{l}$ 128 ready for GC/MS/MS analysis.

\section{Gas Chromatography/Mass Spectrometry and quantification}

130 The acrylamide content was determined by gas chromatography - tandem mass 131 spectrometry (GC/MS/MS). Brominated sample extracts were analyzed on a 132 Thermoquest Trace 2000 gas chromatograph coupled to Finnigan PolarisQ ion trap 133 mass spectrometer. The chromatograph was equipped with fused silica column type 134 DB $5(25 \mathrm{~m} \times 0.25 \mathrm{~mm} \times 0.25 \mu \mathrm{m})$. The operating conditions of GC-MS were as 135 follows: helium flow $0.8 \mathrm{ml}$, initial oven temperature $65^{\circ} \mathrm{C}(1 \mathrm{~min})$; then raised $15^{\circ} \mathrm{C}$ min $136{ }^{1}$ to $170^{\circ} \mathrm{C}$; then at $5^{\circ} \mathrm{C} \mathrm{min}^{-1}$ to $200^{\circ} \mathrm{C}$; finally at $40^{\circ} \mathrm{C} \mathrm{min}^{-1}$ to $280^{\circ} \mathrm{C}(5 \mathrm{~min})$. The GC137 MS interface transfer line was held at $280^{\circ} \mathrm{C}$. Mass spectrometer was running in $\mathrm{ms}^{2}$ 138 mode with the following ions selected for secondary fragmentation: $\mathrm{m} / \mathrm{z} 152$ for 2139 bromopropenamide and $\mathrm{m} / \mathrm{z} 155$ form 2-brompropenamide $\mathrm{d}^{3}$. Comparison of the 140 integrated abundances of the daughter ions of the unlabeled $(\mathrm{m} / \mathrm{z} 135)$ and labeled 141 (m/z 137) compounds provided data for the quantification of the acrylamide (Schieberle 142 and Grosch, 1987). The response factor was calculated in a blank sample spiked with 143 a known amount of unlabeled and labeled acrylamide in three different ratios: 250:50; $144250: 250 ; 250: 500 \mathrm{ppb}$ (Sen et al. 1991). The average response factor was calculated 145 at a value close to one $(1.01 \pm 0.02)$ therefore was omitted in further calculations.

\section{Measurement of sample colour}


147 Colour was measured with a Spectro-Pen (Dr Lange, Poland) in the $L^{*}, a^{*}, b^{*}$ modes, 148 which provide uniform colour differentiation in relation to visual differences. $L^{*}, a^{*}$ and $149 b^{*}$ are chromaticity coordinates, where $L^{*}=$ the lightness of the colour, positive $a^{*}=$ red 150 colour, negative $a^{*}=$ green, positive $b^{*}=$ yellow and negative $b^{*}=$ blue. Because the 151 surface of the potato snacks are not uniform in a colour and shape, colour 152 measurements were performed after milling of $10 \mathrm{~g}$ of the sample, where the optical 153 probe was placed over in a central position. Results are reported as an average of 3 154 measurements.

\section{Results and discussion}

\section{Influence of time and temperature on acrylamide formation}

157 Production of low-fat potato snacks consisted of two major technological processes:158 extrusion cooking and roasting. As has been demonstrated in the aforementioned 159 paper (Majcher and Jelen 2005) the roasting process is a crucial phase for developing 160 Maillard reaction flavor products. Therefore, the authors chose to leave the extrusion 161 parameters stable and consider only the influence of varying temperatures and roasting 162 times. Ten potato snacks samples were obtained. Five were obtained using a constant 163 time of 45 minutes, but varying the roasting temperatures: $130 ; 140 ; 150 ; 160 ; 170^{\circ} \mathrm{C}$. 164 Five were obtained using a constant temperature of $130^{\circ} \mathrm{C}$, but varying the roasting 165 times: 45; 55; 65; 75 and 85 min. For each product the acrylamide content was 166 calculated in triplicates and presented as a mean value with standard deviation. The 167 results are presented in Figure 1.

\section{8 [Insert Figure 1 about here]}

169 The average amount of acrylamide formed in low-fat potato snacks using our original 170 recipe when the roasting process is performed at $130^{\circ} \mathrm{C}$ for $45 \mathrm{~min}$ was estimated at $171489 \mu \mathrm{g} \mathrm{kg}^{-1} \pm 26 \mu \mathrm{g} \mathrm{kg}^{-1}$. This amount is comparable to acrylamide content in products 
172 such as biscuits, crackers $\left(\sim 423 \mu \mathrm{gg}^{-1}\right)$ or French fries $\left(\sim 537 \mu \mathrm{g} \mathrm{kg}^{-1}\right)$ but almost

173 three times less than in potato chips $\left(\sim 1312 \mu \mathrm{gg}^{-1}\right)(\mathrm{WHO} 2002)$.

174

175 Changes in roasting conditions showed that the amount of acrylamide is highly 176 influenced by both temperature or heating time, however an increase in temperature 177 had a stronger effect than an increase in time. Ten minutes of additional roasting time 178 beyond $45 \mathrm{~min}$ doubled the amount of acrylamide, whereas $10^{\circ} \mathrm{C}$ increase in 179 temperature from $130^{\circ} \mathrm{C}$ to $140^{\circ} \mathrm{C}$ increased the acrylamide content more than five 180 times. The longest time used for the roasting (85 min) caused a lower amount of 181 acrylamide formation in low-fat potato snacks $\left(2010 \mu \mathrm{g} \mathrm{kg}^{-1} \pm 64.5 \mu \mathrm{g} \mathrm{kg}^{-1}\right)$ than the 182 smallest raise of temperature from $130^{\circ} \mathrm{C}$ to $140^{\circ} \mathrm{C}\left(2767 \mu \mathrm{g} \mathrm{kg}{ }^{-1} \pm 93.9 \mu \mathrm{g} \mathrm{kg}^{-1}\right)$. This 183 work indicates that to have a lower acrylamide content in potato based products using 184 a longer time at a lower heating temperature is more satisfactory than using a higher 185 temperature. Ehling and Shibamoto in 2005 obtained similar results by performing 186 experiments on model systems using a different ratio of asparagine and D-glucose and 187 found the acrylamide content to be greater using higher temperatures rather than 188 longer heating times.

189

190 Further analysis of the results showed that the amount of acrylamide continued to 191 increase during entire experiment with variable time as well as increasing temperature 192 but only up to $160^{\circ} \mathrm{C}$, at which point any further increase did not change significantly 193 the acrylamide formation. Compared to fried regular potato chips containing a high 194 amount of fat, described by Pedereshi at al (2005), the average acrylamide content 195 increased $\sim 58$ times as the frying temperature increased from $120^{\circ} \mathrm{C}$ to $180^{\circ} \mathrm{C}$. Their 196 results gave no indication that acrylamide formation might slow significantly at some 197 point although the temperature continued to rise. This is opposite to the findings of the 198 authors, which indicate acrylamide formation recessed at $160^{\circ} \mathrm{C}$ At that moment either 
199 one of acrylamide substratum (i.e. asparagine or reducing sugars) had been all 200 exploited or acrylamide might take part in further Maillard reactions. Ehiling and 201 Shibamoto (2005) who experimented on model systems of asparagine and glucose 202 also noted an increase of acrylamide formation with a rise in temperature but only up to 203 a certain point, after which the level of acrylamide started to decrease. Their results 204 showed that heating above $160^{\circ} \mathrm{C}$ for a period of $45 \mathrm{~min}$ reduced acrylamide level as it 205 started to decompose. Although it could be considered as a way to decrease 206 acrylamide content in foods, products obtained with such a high temperature or with 207 such a long time of heating are generally unacceptable to the consumer.

Correlation between colour and acrylamide content in low-fat potato snacks in a function of roasting time and temperature

210 In a second experiment, the effect of colour development and acrylamide formation 211 were studied. Samples roasted at 5 different temperatures $(130,140,150,160$ and $212170^{\circ} \mathrm{C}$ ) and 5 different times $(45,55,65,75$ and $85 \mathrm{~min}$ ) were measured for the 213 intensity of lightness $\left(L^{*}\right)$, redness $\left(a^{*}\right)$ and blueness $\left(b^{*}\right)$ and correlated with 214 acrylamide content at $p<0.005$. Each colour measurement was performed in triplicates 215 and presented as a mean value with calculated standard deviation.

217 Measurements of $L^{*}$ value showed that with increasing time of roasting, lightness of the 218 sample was decreasing as well as with temperature increase but only up to $160^{\circ} \mathrm{C}$. 219 Higher temperatures did not change significantly the level of lightness. On the contrary 220 acrylamide content was increasing during time extension as well as with temperature 221 increase. However, by increasing the temperature from $160^{\circ} \mathrm{C}$ to $180^{\circ} \mathrm{C}$ the acrylamide 222 content did not rise. Calculated correlation coefficient equal to $r^{2}=-0.995$ for time 223 variable and $r^{2}=-0.947$ for temperature change proved that there is a high reverse 224 linear correlation between lightness of the product $\left(L^{*}\right)$ and acrylamide content $(\mathrm{A})$ as a 225 function of time $(\mathrm{t}): \uparrow \top \rightarrow \downarrow L^{*} \uparrow A$ and temperature $(\mathrm{T}): \uparrow t \rightarrow \downarrow L^{*} \uparrow A$ (Figure 2). 
226 [Insert Figure 2 about here]

227

228 The second colour value of low-fat potato snacks, when measured at different 229 temperatures and roasting times, demonstrated an increase of redness $\left(a^{*}\right)$ either with 230 temperature or time change. However, an increase in the red colour intensity was 231 much more constant with time prolongation whereas change in temperature resulted in 232 substantial increases at the beginning of the heating but only till it reached $150^{\circ} \mathrm{C}$, after 233 which it remained without further difference. The analogous situation with acrylamide 234 concentration effected again with high correlation coefficients between $a^{*}$ value and 235 acrylamide content: $r^{2}=0.996$ for changes in a roasting time $\left(\uparrow t \rightarrow \uparrow a^{*} \uparrow A\right)$ and $r^{2}=$ 2360.968 for roasting temperature $\left(\uparrow \top \rightarrow \uparrow a^{*} \uparrow A\right)$ (Figure 3 ).

237 [Insert Figure 3 about here]

238

239 The third value of colour measurement - yellowness $b^{\star}$, was increasing constantly 240 when applying longer heating time and it was highly correlated with acrylamide 241 concentration in a product with correlation coefficient calculated as $r^{2}=0.998$. On the 242 contrary, application of higher roasting temperatures gave an increase of $b^{*}$ values only 243 at the beginning of heating at $140^{\circ} \mathrm{C}$; after that the intensity of yellow colour started to 244 decrease in opposition to the acrylamide content, $r^{2}=0.097$ (Figure 4). Consequently 245 measurement of yellowness was not considered to be a good indicator of acrylamide 246 content in this type of products.

247 [Insert Figure 4 about here]

248 In a recent paper Gökmen et al. (2006) showed that in potato chips the values of $L^{*}$ 249 and $b^{*}$ decreased with temperature and time studied whereas the value of $a^{*}$ increased 250 to certain point and then, depending on temperature, either started to decrease or 251 stayed at the same level. In this study only redness of the product and acrylamide 
252 content was found to be correlated, however the same authors concluded that the 253 complexity of Maillard reaction in which acrylamide is considered to be formed as a 254 intermediate could not be explained by a simple linear regression model but rather 255 required explanation be a more complex quotation involving rate constants determined experimentally for each product. In another paper, Pedrechi at al. (2005) reported that $L^{*}$ and $b^{*}$ did not show significant changes during frying of potato chips, however a coffee. Studies on another potato product such as French fries (Taubert et al. 2004) showed correlation of the colour development and acrylamide content only when a small surface of the product was studied but no correlation was observed for large surface material. Results for low-fat potato snacks reported in this paper were more similar to those obtained by Gökmen et al. (2006) who studied wheat flour, where the intensity of lightness decreased with time at all temperatures considered, and in most cases the intensity of redness $a^{*}$ and yellowness $b^{*}$ increased which was correlated with acrylamide content. Most of the papers (Pedreschi et al. 2005, Gökmen et al. 2006,

275 Shibamoto (2005) demonstrated a correlation of browning colour and acrylamide 276 formation, however their method of colour measurement was based on spectroscopy 277 analysis and involved much more time in sample preparation and measurement. 278 Similar results were obtained by Pedreschi et al. (2006) who studied ways of reduction 279 of acrylamide content in fried potato strips and at the same time correlated it with 
280 colour development. They noted a significant correlation between colour represented 281 by $L^{*}$ and $a^{*}$ values and acrylamide content.

282

283 Mustafa et al. (2005), during studies on rye crisp bread, observed a correlation 284 between acrylamide content and colour expressed with $a^{*}$ and $b^{*}$ values in the time 285 and temperature experiment but found no correlation when acrylamide precursors were 286 added. They concluded that asparagine is contributing to the pathway leading to 287 acrylamide but its effect on colour formation is limited.

288

289 The results presented here show that acrylamide is formed also in low-fat potato 290 snacks, and may suggest that the lower fat content in such products does not influence 291 acrylamide formation. Temperature is the most important factor for acrylamide 292 formation in low-fat potato snacks. At the same time it has been proven that 293 measurement of colour expressed as value of lightness, $L^{*}$, and redness, $a^{*}$, could be 294 a good estimator of acrylamide content in food products.

295

296 References

297

298 Ahn J.S., Castle L., Clark D.B., Lloyd A.S., Philo M.R., Speck D.R. (2002) Verification 299 of the findings of acrylamide in heated foods. Food Addit. Contam., 19, 1116-1124.

300 Becalski A., Lau B.P.-Y, Lewis D., Szaman S.W. (2003) Acrylamide in foods: 301 Occurrence, sources and modeling. J. Agric. Food Chem. 51, 802-808.

302 Belitz H.D., Grosch W., Schieberle P. (2004): Food Chemistry, Springer, Germany. 303 Castle L., (1993): Determination of acrylamide monomer in mushrooms grown on 304 polyacrylamide gel. J. Agric. Food Chem. 41, 1261-1263. 
305 Ehiling S., Shibamoto T. (2005): Correlation of acrylamide generation in thermally 306 processed model systems of asparagine and glucose with colour formation, amounts of 307 pyrazines formed, and antioxidative properties of extracts. J. Agric. Food Chem. 53, $308 \quad 4813-4819$.

309 Elmore J.S., Koutsidis G., Dodson A.T., Mottram D.S., Wedzicha B.L. (2005): The 310 effect of cooking on acrylamide and its precursors in potato, wheat and rye. Adv. Exp. 311 Med. Biol. 561, 255-269.

312 Friedman M. (2003): Chemistry, biochemistry and safety of acrylamide. A review. J. 313 Agric. Food Chem. 51, 4504-4526.

314 Gökmen, V., H.Z. Şenyuva, B. Dülek, A.E. Çetin (2007): Computer vision based image 315 analysis for the estimation of acrylamide level of potato chips and french fries. Food 316 Chemistry 101, 791-798.

317 Gökmen V., Hamide Z. Şenyuva (2006) Study of colour and acrylamide formation in 318 coffee wheat flour and potato chips during heating. Food Chemistry 238-243.

319 IRAC. Some Industrial Chemicals; International Agency for Research on Cancer, Lyon, 320 France, 1994.

321 Majcher M.A., Jeleń H.H. (2005) Identification of potent odorants formed during the 322 preparation of extruded potato snacks. J. Agric. Food Chem., 53, 6432-6437.

323 Mottram D.S., Wedzicha B.L., Dodson A.T. (2002) Acrylamide is formed in the Maillard 324 reaction. Nature 2002, 419-450.

325 Mustafa A., Andersson R., Rosen J., Kamal-Eldin A., Aman P. (2005): Factors 326 influencing acrylamide content and colour in rye crisp bread. J. Agric. Food Chem. 53, $327 \quad 5985-5989$.

328 Papadakis S.E., Abdul-Malek S., Kamdem R.E., Yam K.L. (2000) A versatile and 329 inexpensive technique for measuring colour of foods. Food Technology, 54, 48-51. 
330 Pedreschi F., Moyano P., Kaack K., Granby K. (2005): Colour changes and acrylamide 331 formation in fried potato slices. Food Res. Inter. 38, 1-9.

332 Pedreschi F, Kaack K, Granby K (2006): Acrylamide content and colour development 333 in fried potato strips. Food Res. Inter. 39, 40-46.

334 Schieberle P., Grosch W., (1987) Quantitative analysis of aroma compounds in wheat 335 and rye bread crust using a stable isotope dilution assay. J. Agric. Food Chem., 35, $336 \quad 252-257$.

337 Sen A., Laskawy G., Schieberle P., Grosch W., (1991) Quantitative determination of 338 (E)- $\beta$-damascenone in foods using stable isotope dilution assay. J. Agric. Food Chem., $33939,757-759$.

340 Senyuva, H.Z., Gökmen V., (2005) Study of acrylamide in coffee using an 341 improved liquid chromatography mass spectrometry method: Investigation 342 of colour changes and acrylamide formation in coffee during roasting, Food 343 Add. and Cont. 22, 214-220.

344 Taubert D., Harlfinger S., Henkes L., Berkels R., Schomig E. (2004) Influence of 345 processing parameters on acrylamide formation during frying of potatoes. J. Agric. 346 Food Chem., 52, 2735-2739.

347 WHO (2002): Health implications of acrylamide in food, Report of a Joint FAO/WHO 348 Consultation, 25-27 June 2002. Final Report 17 September 2002. 
1

2

3

4

5

6

7

8

9

10

11

12

13

14

15

16

17

18

19

20

21

22

23

24

25

26

27

28

29

30

31

32

33

34

35

36

37

38

39

40

41

42

43

44

45

46

47

48

49

50

51

52

53

54

55

56

57

58

59

60

Figure 1. Influence of roasting time (temperature even $\left.=130^{\circ} \mathrm{C}\right)(\mathrm{A})$ and temperature $($ time even $=45 \mathrm{~min})(\mathrm{B})$ on acrylamide formation during preparation of low-fat potato snacks.

(A)

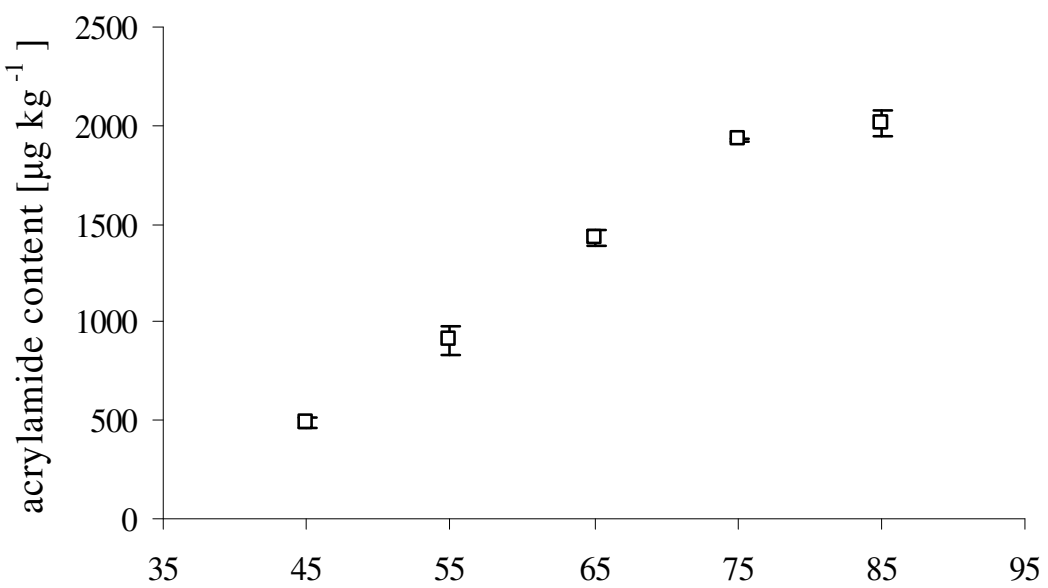

(B)

roasting time $[\mathrm{min}]$

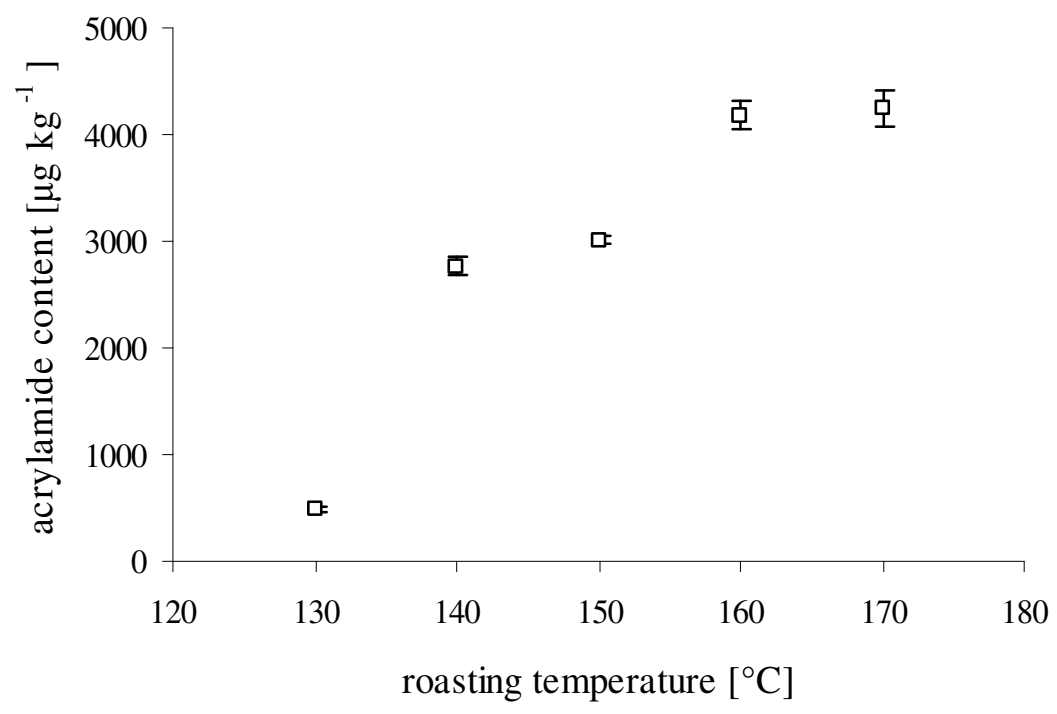


Figure 2. Acrylamide content and color lightness $L^{*}$ in a function of roasting time (A) and temperature (B). (A)

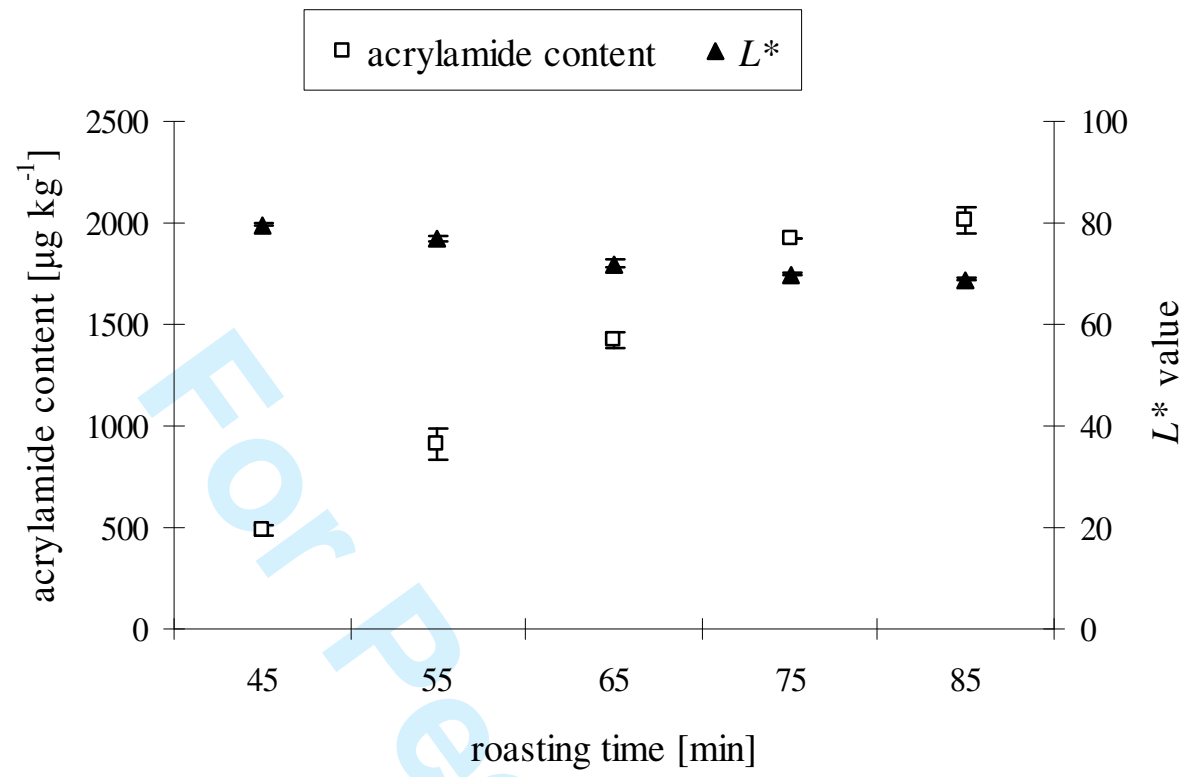

(B)

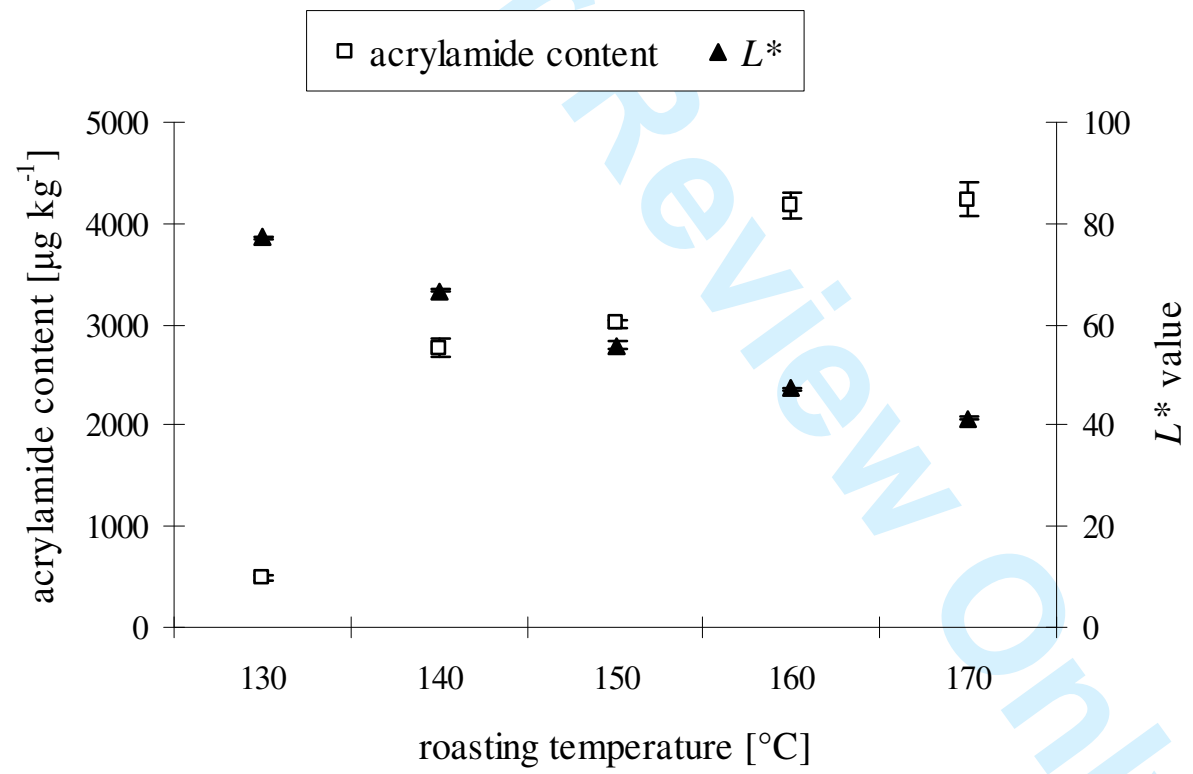


Figure 3. Acrylamide content and color redness $a^{*}$ in a function of roasting time (A) and temperature (B). (A)

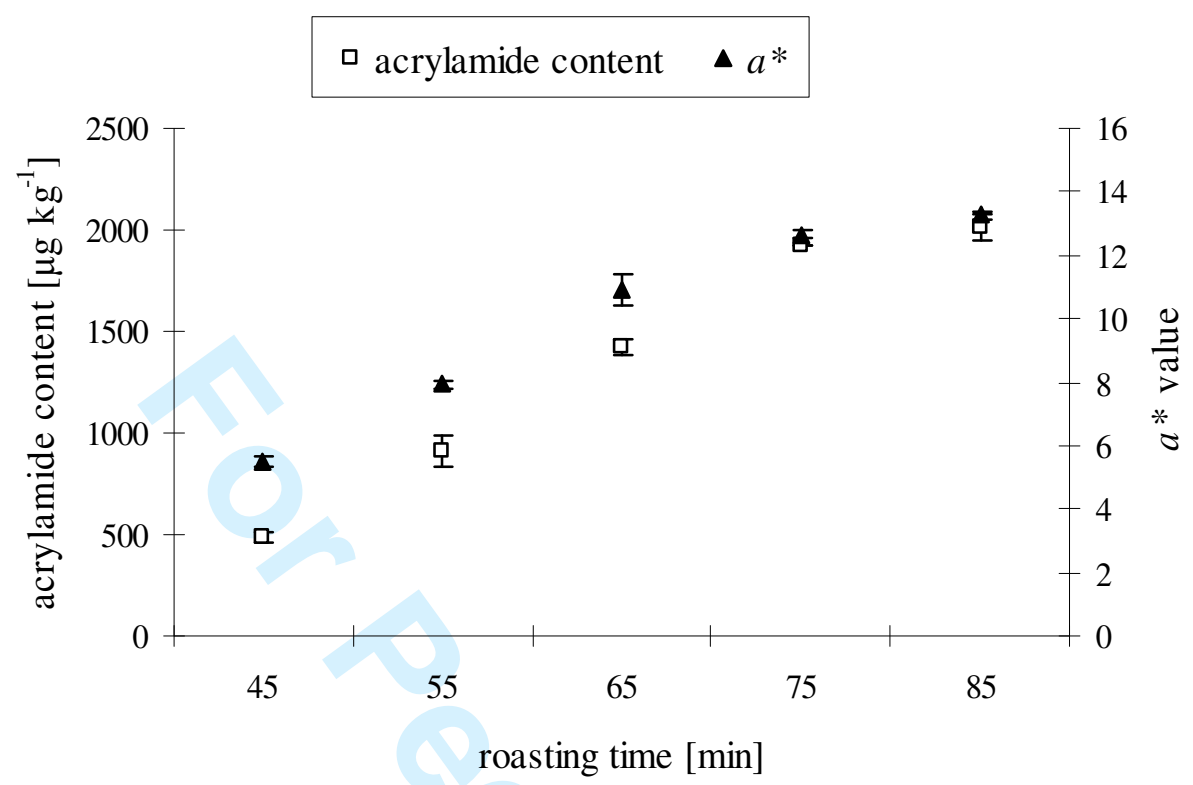

(B)

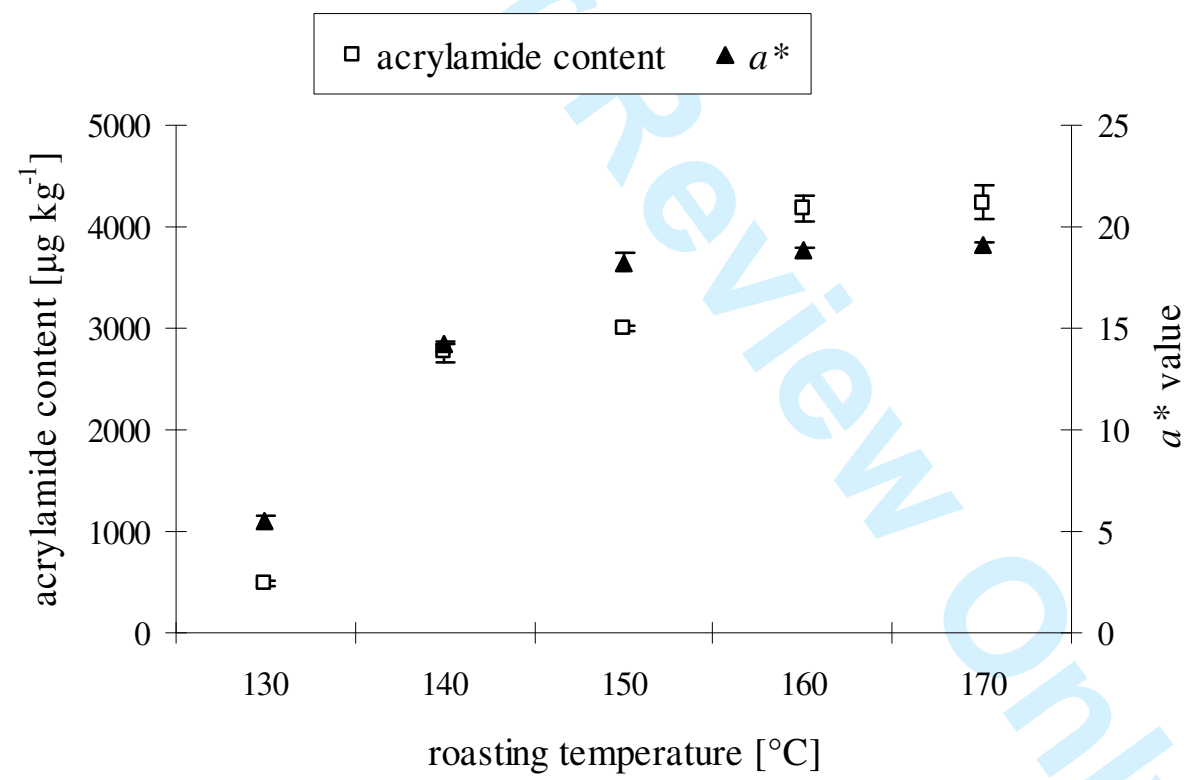


Figure 4. Acrylamide content and color yellowness $b^{*}$ in a function of roasting time (A) and temperature (B).

(A)

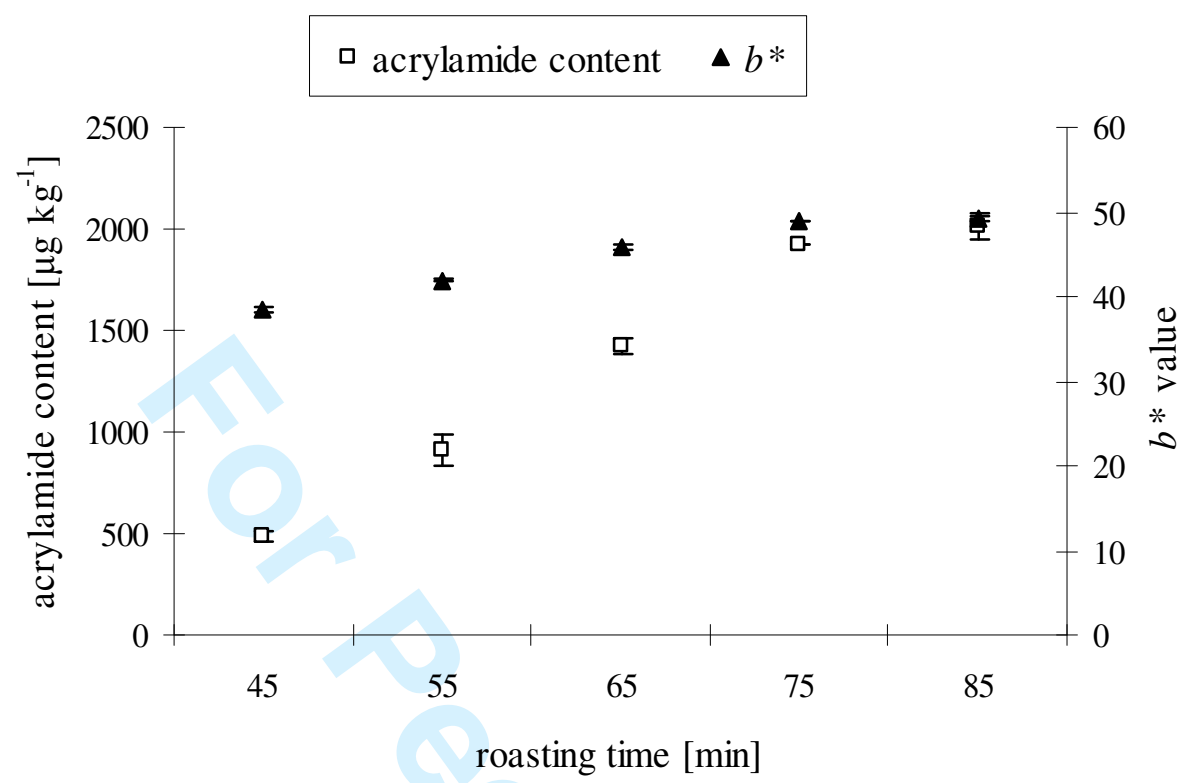

(B)

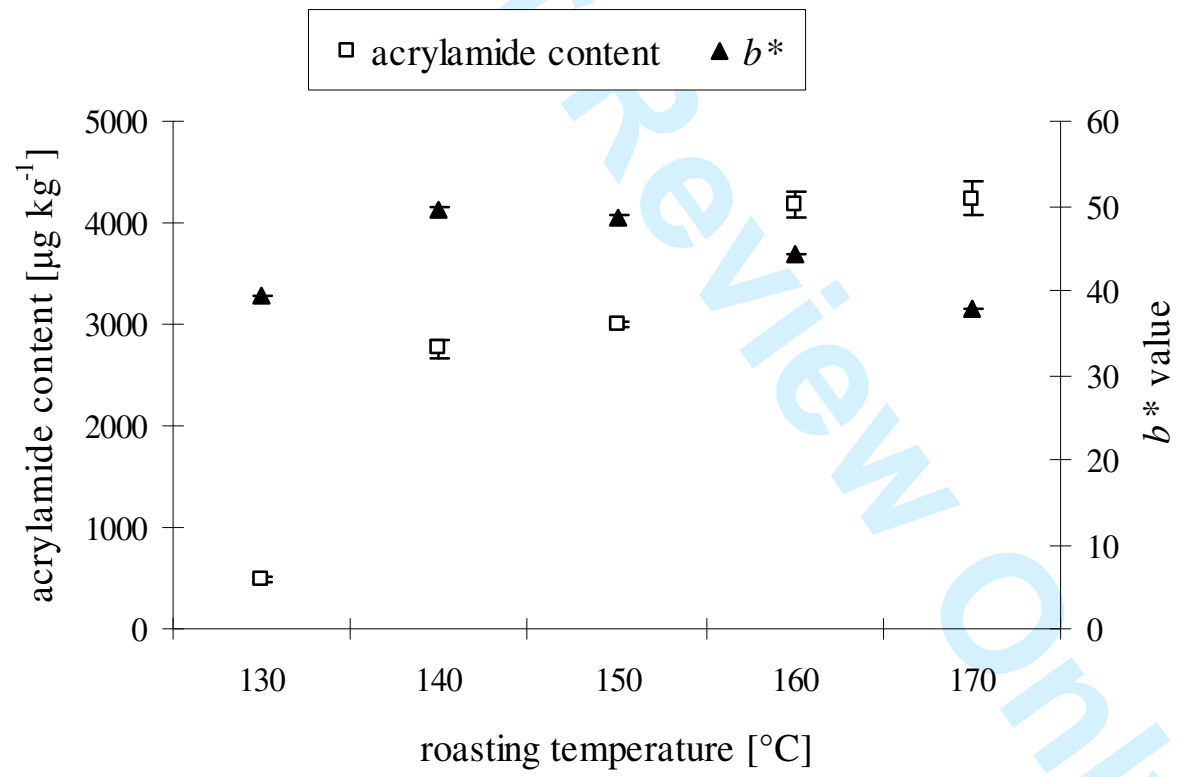

